\title{
Building network-level resilience to resource disruption from flooding: Case studies from the Shetland Islands and Hurricane Sandy
}

\author{
Shaun Brown ${ }^{1}$ and Richard Dawson ${ }^{2, a}$ \\ ${ }^{1}$ Ordnance Survey, Adanac Drive, Southampton, SO16 OAS, United Kingdom \\ 2 School of Civil Engineering and Geosciences, Newcastle University, Newcastle upon Tyne, NE1 7RU, United Kingdom
}

\begin{abstract}
Flood events, at a range of scales, have led to disruption of resources such as water, food, materials and goods are vital to the safety, health and livelihoods of individuals and communities. Increasing interdependencies across infrastructures and supply chains pose substantial challenges for those seeking to move resources, and flood risk managers aiming to reduce the disruption to resource movements before, during and after a flood event. This paper introduces a quantitative resource model that embeds input-output relationships of supply and demand within a spatial network model which enables the impacts of a spatial hazard, such as a flood, to be evaluated. The model has been tested in the Shetland Islands and New York City. The analysis supports observations that a single flood event can disrupt the movement of resources far beyond the flooded area. Disruption of critical sectors can rapidly lead to collapse of the entire system given certain conditions. Resource management strategies, such as diversifying supply chains, reduced clustering of industry and storing supplies locally are shown to reduce the magnitude of the initial impact, and slow the propagation of the disruption through the system - providing useful insights to flood risk managers and planners.
\end{abstract}

\section{Introduction}

Recent floods, other natural disasters and human activities, have highlighted the impact of infrastructure disruption on supply chains and the movement of resources (such as goods, water, energy, materials and waste) at a range of scales. The movement of these resources helps ensure the health of people, their communities and economy. For example, during the summer and autumn of 2011 Thailand was severely disrupted by prolonged flooding that occurred in the Chao Praya River Basin. The damage is estimated to be more than US $\$ 45$ billion [1], making it one of the most costly disasters in history. Apart from the direct impact on the Thai society and economy, the floods had global effects on the production and supply of a wide range of goods: about $25 \%$ of all hard drives in the world are manufactured in Thailand [2].

Similarly, the reduction in energy generation capacity in Japan that resulted from the nuclear accident that occurred with the Fukushima - Daishi power plant after the 2011 tsunami reduced the production capacity of Japanese industry, with a slow of materials and supplies to downstream industries - including car assembly plants in the Northeast of England [3]. Hurricanes Katrina and Sandy both impacted upon resource movements in New Orleans and New York respectively after disrupting multiple infrastructure services simultaneously. In the UK in September 2000, within four days a blockade of six of the nine oil refineries led to a nationwide shortage of fuel: over 3000 petrol stations were reported to have run out. This led to a cancellation of mail delivery, shortage of food availability and other knock on impacts.

As infrastructure systems become increasingly interdependent, the potential scale of disruption to infrastructure, the subsequent cascading disturbance of resource flows and the resultant impact on society becomes increasingly challenging to analyse. This paper introduces a new resource modelling approach to analyse the risks associated with resource disruption, resulting from disruptive events. Although the method could be applied to a range of hazards, our focus is on a possible flood event and associated resource disruption in the Shetland Islands, off the north coast of Scotland.

\section{Methodology}

\subsection{Resource model}

Our resource model brings together two established modelling methodologies: input-output (I-O) modelling and network analysis. The I-O model describes the flow of resources between different industrial sectors and thus captures interdependencies between elements of a system [4] as critical industries share significant resources, and the flow of goods and information constantly takes place among these different industrial sectors [5].

\footnotetext{
${ }^{\mathrm{a}}$ Corresponding author: richard.dawson@newcastle.ac.uk
} 


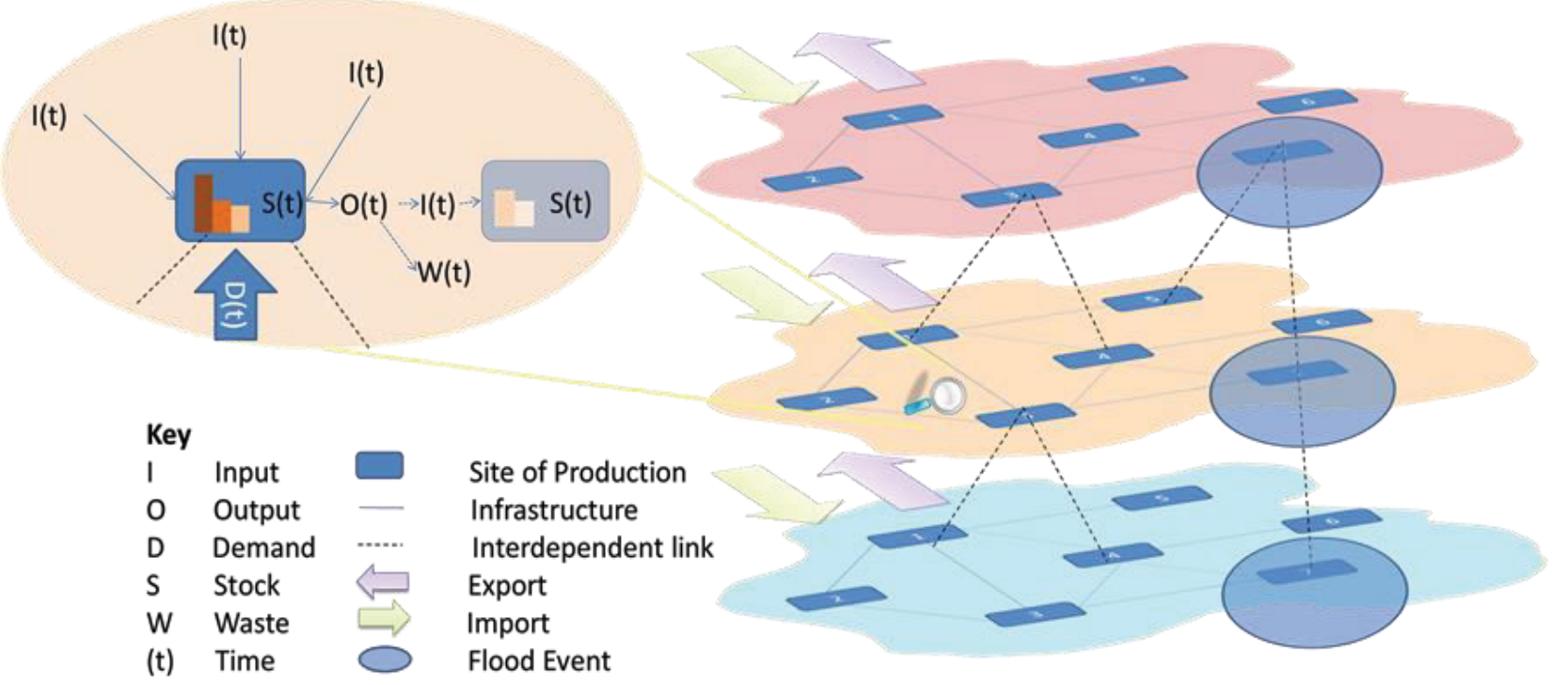

Figure 1. Schematic of the resource model.

Infrastructure systems including transport, energy, water and waste mediate the movement of these resources. Because the elements of these systems interact with each other and with their environment; they can then be analysed using network theory [6,7]. To understand resource flows across these networks we have extended traditional network modelling approaches to capture inputs, $I$, outputs, $O$, as well as stocks, $S$ and flows through time, $t$. The model enables a range of alternative resource management strategies to be explored (Figure 1).

The I-O relationships describe the input requirements per unit of output, or what each sector requires from the other sectors in a system to produce one unit of its product [8]. This describes the interdependencies between different infrastructure and industries. The input output relationship is defined as:

$$
x=C x+d
$$

where $x$ is the desired production, $C$ is the consumption matrix (see for example Table 1) and $d$ is the final demand. The equilibrium production is calculated using:

$$
x=(\mathrm{I}-C)^{-1} d
$$

where $\mathrm{I}$ is the identity matrix and $\left(\mathrm{I}-\mathrm{C}^{-1}\right.$ is generally referred to as the Leontief Inverse, or the total requirements matrix [9] which captures both the direct and indirect input requirements into the system [10].

An I-O relationship highlights how different industrial sectors are affected by impacts in other parts of the system. For example, industry A requires $x$ from industry $\mathrm{B}$ and $y$ from industry $\mathrm{C}$. In turn industry A supplies industries B, D and E with $z$ of its own outputs. Thus, a disruption in supply from Industry B will have a knockon effect to production in $\mathrm{A}$, which subsequently cascades back to industry B and also industries D and E.

Each industrial site is represented as a node in the network, and connected via a link to other relevant sites if an I-O relationship exists. So for example in Figure 1, the magnified view of one node shows it has three inputs, which provide a given quantity of a resource at each time step. In this instance, the singular output acts as an input for another industrial activity. The model also brings in a notion of reserve stocks at each of the sites; enabling each different site to have different stocks of resources level. In addition to resource flow properties, each node is assigned a relative spatial location for flood risk analysis. The baseline assumes that each site can provide the resources that are requested, and that at each time step a single unit of resource is produced at each site.

The model has been implemented in the python programming language; the Numpy extension was used to facilitate the matrix analysis [11] required for the I-O analysis, and the NetworkX extensions for the formation and operation of networks [12] which supports the construction and analysis of the network model.

\subsection{Vulnerability analysis}

The spread of networks and buildings across and within areas at risk greatly influences impacts of events like flooding. Typically input output data is not provided at a spatial resolution that is suitable for impacts analysis within areas of heterogeneous activity. Thus, an important step is the disaggregation of input output data. To achieve this, census and business data was used to provide information on the number people employed within a specific industry at a census geographical unit. To produce the supply and demand data for the modelled sectors of the economy at a census geography level the following steps were taken:

1. Employment data was acquired to provide SIC 4 digit classification of industrial and economic employment in each census ward,

2. This was complemented by census data that provides population profiles within each census geography, and spatial mapping data that provides the location of individual buildings.

3. The number of employees $e_{s}$ for each site of production, $s$, in all census geographical units was normalised according to the total number of employees across the whole economy, $E$. 
4. The proportion of employees was used as a proxy for estimating the proportion of input, $I$, and output, $O$, from each industrial sector, $j$, in each ward, $s$ :

$$
I_{s, j}=\left(\frac{e_{s}}{E}\right) I_{j} ; O_{s, j}=\left(\frac{e_{s}}{E}\right) O_{j}
$$

5. Similar scaling, by population, can be used to estimate residential demand for services. As with industrial supply and demand this makes the assumption, in the light of no higher resolution information, of uniform demand and productivity per capita.

6. Resource flow input-output relationships are extracted from regional accounting of trade data.

\subsection{Analysis of resource disruption}

Resilience is typically defined as the elastic ability to return to an original state, or capacity to quickly recover from difficulties. A resilient system displays qualities such as staying power, adaptability and flexibility [13]. Our interest here is to explore the impact of interdependencies between infrastructures. The model simulates what happens to the wider system when a site of production is disrupted, as well as providing a mechanism to evaluate the effectiveness of strategies to lower the effect of the modelled network failure [14].

Rather than seeking to estimate indirect economic damages from flooding (e.g. [15]), by calculating the economic losses associated with resource disruption, we analyse the resilience of different strategies using some simple metrics of system behaviour that help understand the interdependencies and process of disruption, as well as compare the effectiveness of each strategy.

1. The number of time steps after the initial disruptive event before each site fails

2. The proportion of sectors operating

3. The number of remaining active I-O connections

This latter measure is often used as a proxy to measure the resilience of networked systems [16].

1) Once the reduction in resource stocks, production capacity, network transportation capacity is quantified, the model can be re-run to explore how far the disruption proliferates. This is repeated for a full range of flood levels to produce a vulnerability curve. Equation (2) is used to calculate the vulnerability, defined as the proportion of resource flows remaining at equilibrium. This is a worst case measure - as recovery from the disruption caused may have started by this point:

$$
V=\frac{\sum_{i=1}^{N} I_{i}\left(t=t_{e}\right)+o_{i}\left(t=t_{e}\right)}{\sum_{i=1}^{N} o_{i}\left(t=t_{0}\right)+o_{i}\left(t=t_{0}\right)}
$$

where $N=$ the number of nodes through which resources flow, $I_{i}$ and $O_{i}=$ volume of output for node $i$ across all sectors, $t_{o}=$ the time of initial disruption and $t_{e}$ $=$ time at which resource flows within the system find equilibrium and stabilise.

The equilibrium time is the number of timesteps after the initial disruption that the level of disruption stabilises - the lowest point on Figure 2.

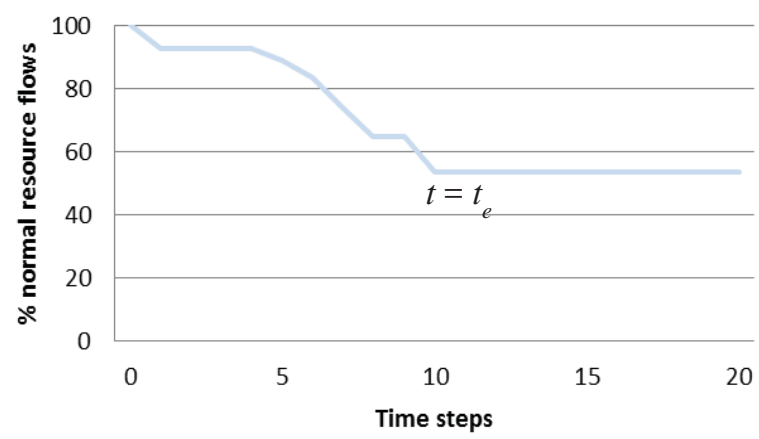

Figure 2. Indicative output, showing the percentage of total resource flows (compared to normal operating conditions) across the system after a disruptive event.

\section{Results}

\subsection{Case study: Shetland Islands}

A preliminary case study in the Shetlands Island has been developed (Figure 3). This data is based solely on intraregion industrial interactions derived from regional accounts [17] and the data described in the methodology section; therefore imports and exports to or from the islands are not taken into account. Only primary and secondary sectors were included within the model. The study site was convenient as the internal economy of the Islands has been well documented and many of the industries are co-located geographically which reduces the complexity of the spatial interactions that need to be represented in the model. This enables the results of this implementation to be more easily interpreted. 


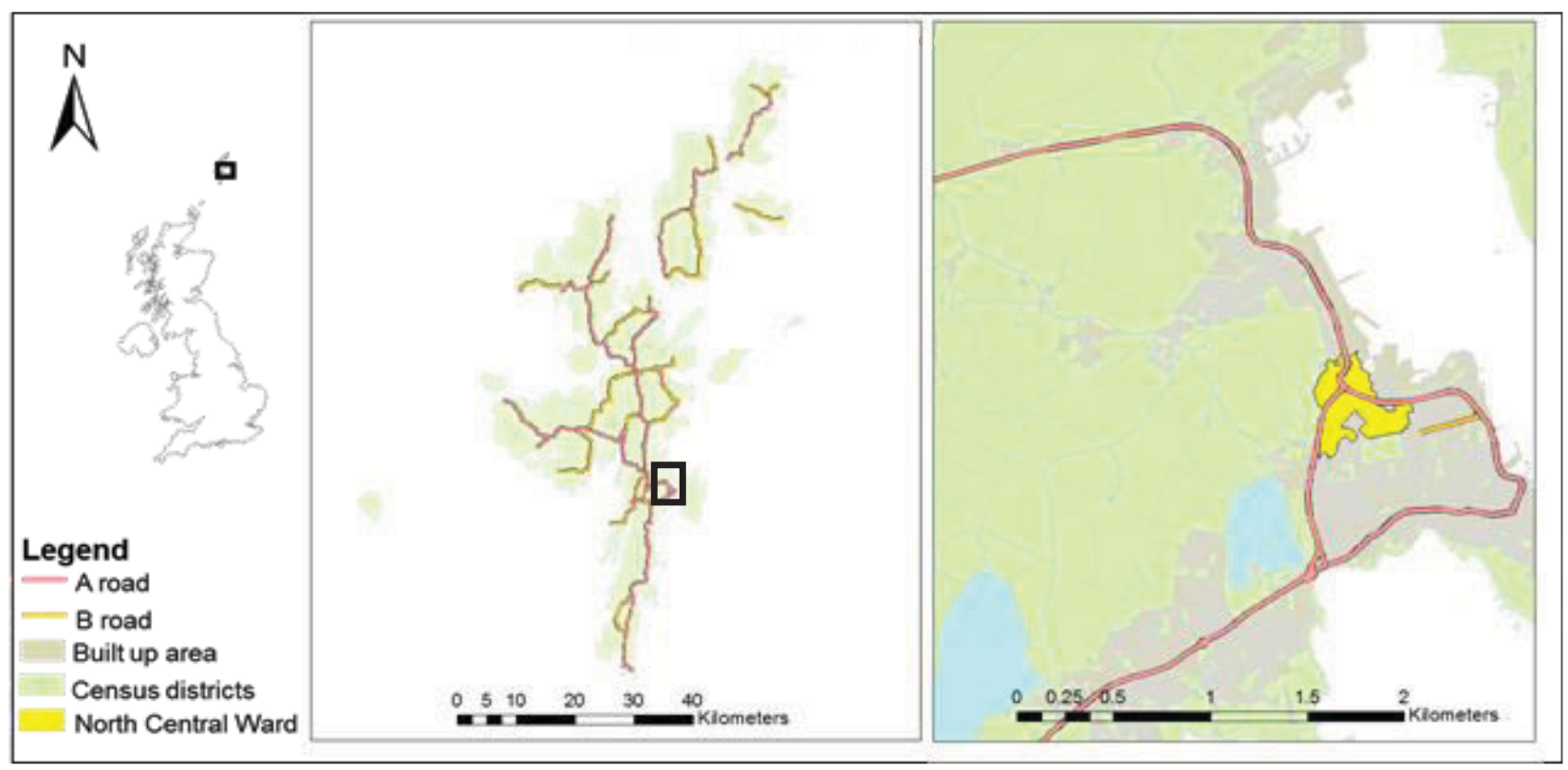

Figure 3. Maps showing (i) the location of the Shetland Islands in the UK, (ii) the location of the capital Lerwick and major transport infrastructure, and (iii) the North Central ward used for this pilot.

Four alternative strategies for resource management were explored in the first instance to examine their relative resilience to a disruptive flood event.

S1. A Just In Time strategy limited onsite storage and deliveries of resource arrived as required at each time step.

$\mathrm{S} 2$. As with $\mathrm{S} 1$, but each node has reserve stock of three units. It is assumed the sites all have the space to house the stock.

S3. "Batch deliveries" of 5 units, rather than a single resource unit, were made - but only every 5 th time step.

S4. As with S3, but each node has an additional reserve stock of three units.

All four strategies were tested against two flood events. In each instance a flood was assumed to impact only one site location. Under each flood event production was assumed to halt completely, existing stocks were assumed to be destroyed and the input and output links severed. Any subsequent impacts were then a result of the system cascade. Two site locations were selected according to their flood risk as documented by [18]:

1. Marine Engineering (ME). Clustered around the capital, Lerwick, close to both the North and South Burn of Gremista which flows through two undersized culverts. These culverts are thought to have increased the probability of flooding from 1 in 200 years, in natural conditions, to 1 in 15 years. Lerwick has also suffered from tidal flooding during "the Braer Storm" of 1993.

2. Distribution (D). A large proportion of the main sites associated with this industry, also near Lerwick, are at potential risk of flooding.

Figure 4 shows how disruption propagates spatially through the island as a result of a disruptive event, whilst Figure 5 shows a timeseries of aggregate resource disruption in the whole region under a number of different scenarios.
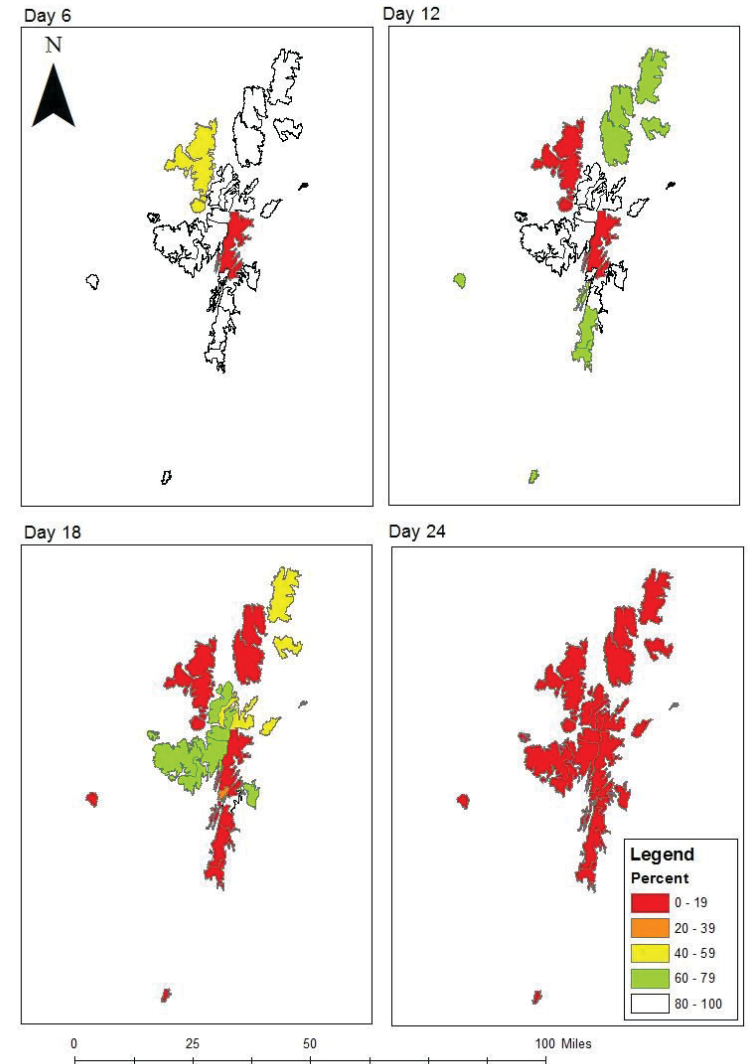

Day 24

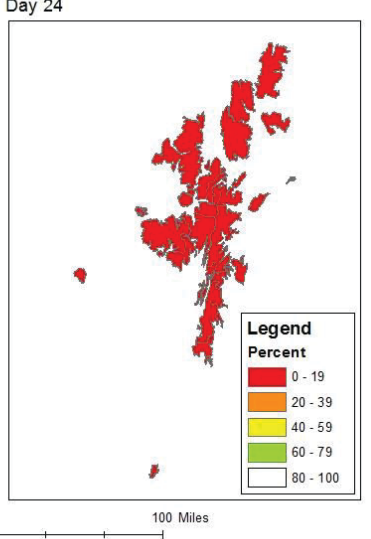

Figure 4 Percentage remaining output by ward 6, 12, 18 and 24 days after a flood event disrupts $15 \%$ of production in the Sandsting census area to the West of Lerwick. 


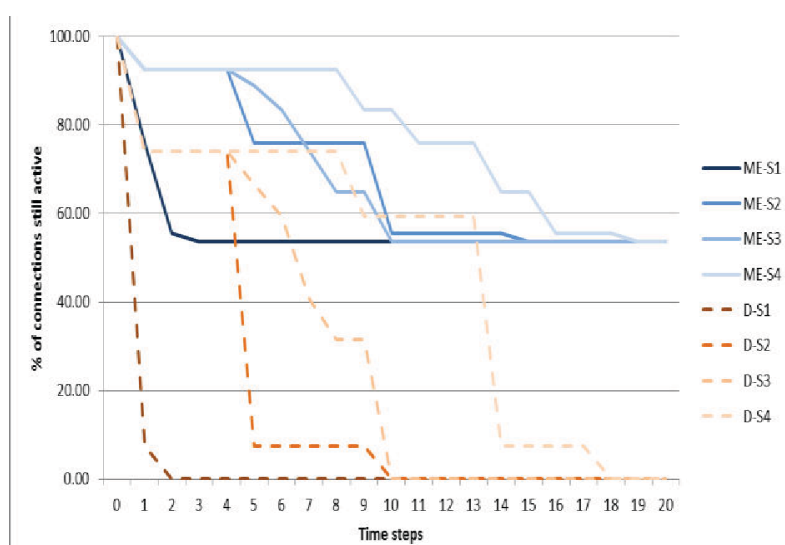

Figure 5 Resource flows across the Shetland Islands after a 1 in 200 year flood disrupts Lerwick North.

Disruption to marine engineering, unsurprisingly, has a less severe overall impact than flooding of distribution and land transportation hubs. Overall, disruption is just over $40 \%$ because key sectors such as construction and distribution remain unaffected by disruption to the marine engineering sector. Significant disruption to key distribution sites, when resources are distributed Just In Time rapidly leads to a cascading failure across all resource movements. This is supported by information in Table 1 that shows the connectivity of each sector, highlighting the potential for cascading impacts.

Reserve stocks, and use of bulk delivery strategies can increase the resilience of the system by delaying the largest impacts of any disruption. Use of reserve stocks not only delays the impacts of disruption, but also slows the rate of disruption propagating through the system. This lag provides time to intervene and take corrective actions to reduce the flood risk from resource disruption.

Bulk deliveries offer some benefit to delay disruption but do not necessarily slow the resource failure cascade. Sensitivity tests (not shown here) show that the quantity and frequency of batch deliveries alters the performance of this strategy. These scenarios consider a flood in Lerwick, and whilst floods elsewhere show similar phenomena the magnitude and timings vary according to the location of the initial disruption and the interdependence between different sectors (Table 1).

\begin{tabular}{|c|c|c|c|}
\hline & $\begin{array}{c}\text { Number of } \\
\text { sites }\end{array}$ & $\begin{array}{c}\text { Sectors } \\
\text { supplied }\end{array}$ & $\begin{array}{c}\text { Sectors } \\
\text { providing }\end{array}$ \\
\hline Agriculture & 4 & 10 & 21 \\
\hline Fish Catching & 6 & 4 & 17 \\
\hline Aquaculture & 12 & 6 & 18 \\
\hline Oil Terminal & 1 & 1 & 17 \\
\hline Mining \& Quarrying & 3 & 7 & 12 \\
\hline Fish processing & 5 & 13 & 16 \\
\hline $\begin{array}{c}\text { Other food \& drink } \\
\text { processing }\end{array}$ & 9 & 17 & 18 \\
\hline Marine engineering & 4 & 6 & 16 \\
\hline Textiles \& crafts & 7 & 11 & 16 \\
\hline Other manufacturing & 9 & 24 & 11 \\
\hline
\end{tabular}

\begin{tabular}{|c|c|c|c|}
\hline $\begin{array}{c}\text { Electricity, gas \& water } \\
\text { supply }\end{array}$ & 6 & 30 & 16 \\
\hline Construction & 11 & 30 & 20 \\
\hline Wholesale & 6 & 17 & 11 \\
\hline Retail & 8 & 21 & 11 \\
\hline Accommodation & 12 & 20 & 17 \\
\hline Catering & 11 & 21 & 19 \\
\hline Ports and Harbours & 8 & 11 & 4 \\
\hline Transportation, sea & 6 & 19 & 15 \\
\hline Transportation, land & 10 & 26 & 8 \\
\hline Transportation, air & 2 & 26 & 18 \\
\hline Oil Supply Services & 1 & 4 & 19 \\
\hline Communication \& supply & 16 & 21 & 15 \\
\hline Financial Services & 2 & 24 & 4 \\
\hline $\begin{array}{c}\text { IT/computer related \& real } \\
\text { estate }\end{array}$ & 10 & 23 & 17 \\
\hline $\begin{array}{c}\text { Technical, Professional, } \\
\text { ther business services }\end{array}$ & 15 & 28 & 9 \\
\hline Public administration & 15 & 18 & 15 \\
\hline School Education & 17 & 0 & 15 \\
\hline College Education & 4 & 1 & 10 \\
\hline Health & 7 & 3 & 16 \\
\hline Social work & 13 & 5 & 9 \\
\hline Other community services & 16 & 24 & 16 \\
\hline
\end{tabular}

Table 1. Resource interconnections

\subsection{Case study: New York}

A second case study was used to analyse and validate the model against the disruption to resource movements in New York City caused by Hurricane Sandy. The case study focuses on the sectors reported in detail in post-event analysis: food supply, fuel, wholesale, retail and households.

The model is set up at the scale of 'community district', of which there are 71 of across five boroughs in New York City (Figure 6). Within the city there are also five major food wholesale markets, the largest of these is Hunts Point (marked on Figure 6) which handles 60\% of the food that passes into New York City [19]. After Sandy it was found that the distribution of food was hampered because the supply of diesel and petrol into New York City was disrupted. This meant that the food could not get from the wholesale markets to retail outlets, and finally to households [19]. A timeline of disruption has been reconstructed from post-flood surveys and other records (Figure 7) and for many of the resources the rate of depletion and details of recovery has been recorded. Figure 8 (after $[19,20]$ ) shows the operational status for fuel terminals, [21] observed that food supplied were depleted within 2-3 days, and [22] recorded the operational status of infrastructure. This provided a dataset for validation of the model timestepping that was not available for the Shetland Islands. The model shows the same patterns and consumption rates as were observed in the resource model. 


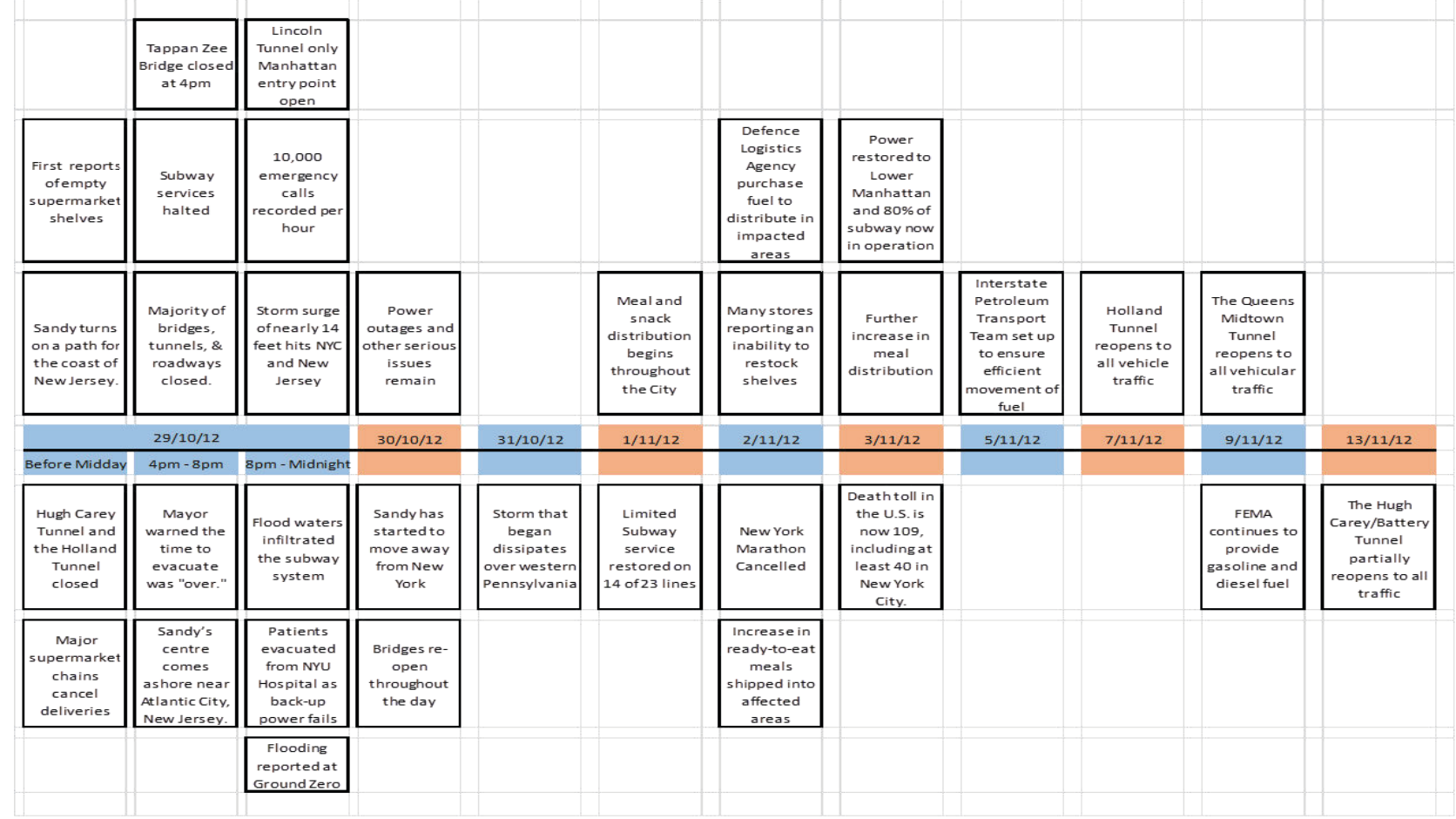

Figure 7. Timeline of Hurricane Sandy, constructed from [22,23,24]
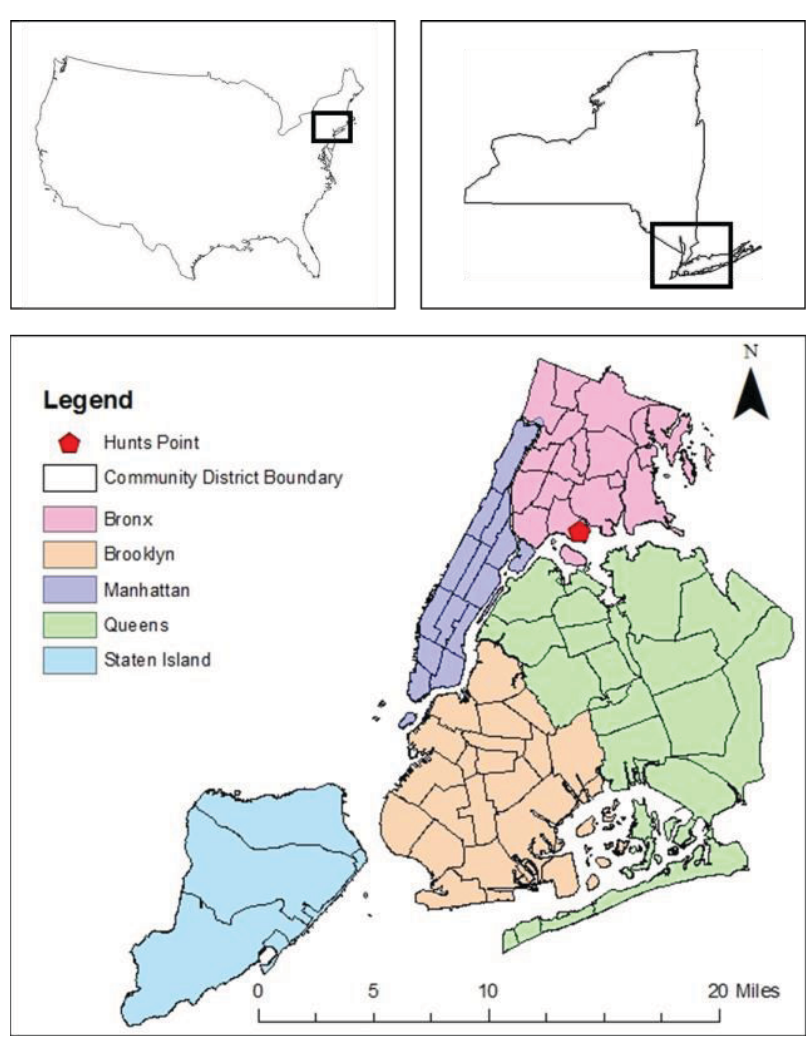

Figure 6. Map of the five boroughs of New York City and their community district boundaries.

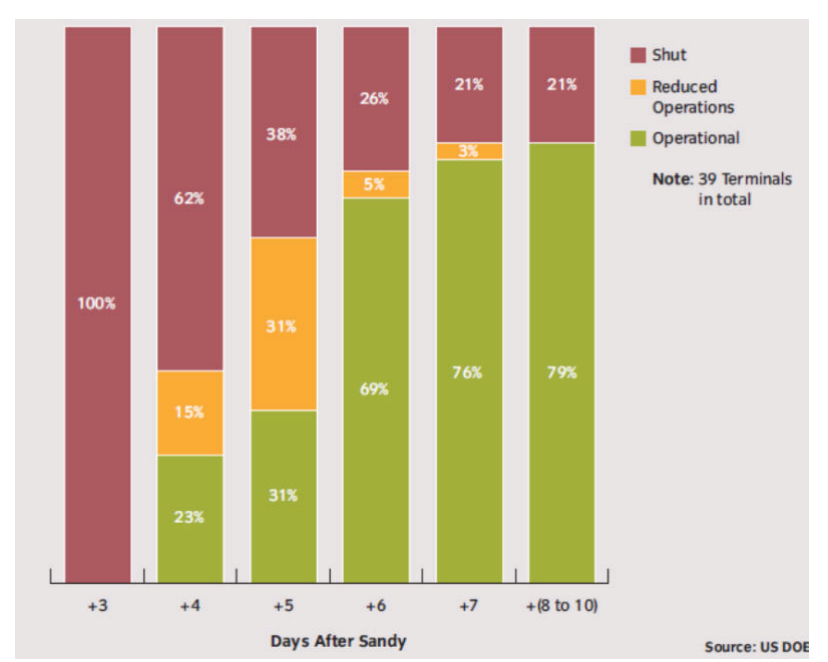

Figure 8. New York Metropolitan Area fuel terminals operational status in the days after Hurricane Sandy (source:

[21]).

Figure 9 shows the resource disruption across NYC for a number of resource management strategies. Bulk deliveries (B), and Just In Time (JIT) are as in the first case study. Other strategies considered the storage of onsite Reserves (Re), Repair and reopening of flood damaged transport links and production sites (Rv), and Rationing (PS) of resources. As with the Shetland Island case study JIT provides the least resilient strategy, with use of reserves and bulk deliveries reducing the rate of impacts. Rationing of supply further slows total resource disruption. However, without any further injection of resources, just repairing flooded infrastructure has little effect in the current resource system. 


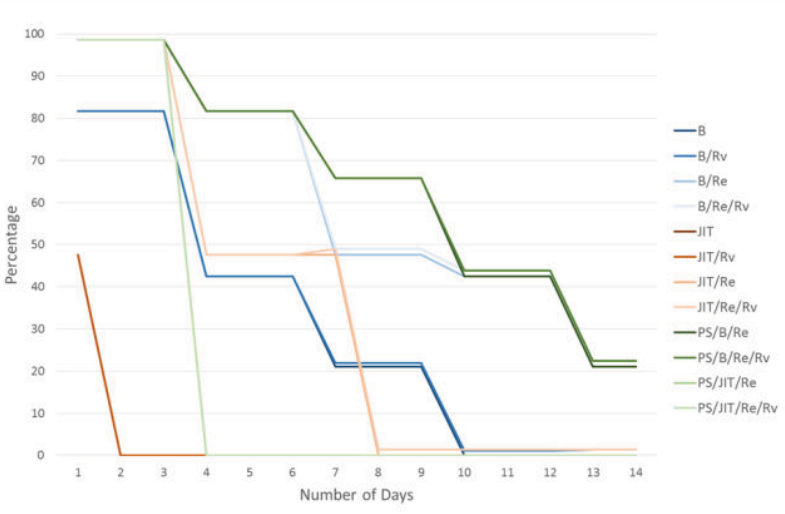

Figure 9. Graph showing aggregate resource disruption (as a percentage of normal output) after $100 \%$ disruption of fuel supplied to New York City.

A number of other flooding and storm scenarios were tested to explore the benefits of diversifying food and fuel supply chains. Addition of an extra fuel supply route into NYC reduces disruption to resource flows by $39 \%$, whilst a more even distribution of food supply across the 5 other centres in NYC reduces disruption by $21 \%$.

\section{Conclusions}

Recognising that maintaining the flow of vital food, materials, fuel, water and other resources before, during and after a flood event is important to ensure community resilience, we have developed and introduced a resource model that couples information on consumption and demand for resources, within an infrastructure network model. This has enabled us to understand resource movements in time and space between different residential and industrial locations. The model has been tested on the Shetland Islands, off the north coast of Scotland, and also to simulate the impacts of Hurricane Sandy in New York City.

This study supports observations from flood events considered in the introduction that a just-in-time approach to resource management reduces system resilience. Overall, the case studies highlight the most flood resilient resource management strategies:

- Minimise use of just-in-time supply chains

- Avoid spatial clustering of industries

- Diversify suppliers and supply routes

- Invest greatest protection in industries with greater connectivity to the wider resource network

- $\quad$ Stockpile reserves, both locally, and regionally and be able to handle bulk deliveries

There are of course challenges to achieving these ideals. Some products have a short shelf life and therefore require frequent deliveries. Storage space has a cost, and this can be even more significant within an urban environment. Similarly, the cost of maintaining a diverse range of suppliers, protecting multiple supply routes, or maintaining multiple heavy industry sites may be prohibitive due to the capital cost of the infrastructure. Bulky deliveries and storage of hazardous products poses a safety risk. A risk-based approach is therefore essential as it is likely to be impractical to design out all resource disruption eventualities.

Further work is transferring and demonstrating how this model can be used within a risk-based framework, exploring the impact of larger scale disruptions (e.g. international supply chain impacts following the East Japan tsunami), and developing a full recovery model to simulate post-event repair and recovery to better support disaster response.

\section{Acknowledgements}

This research has been funded by the Engineering and Physical Sciences Research Council grant: EP/ H003630/1.

\section{References}

1. Aon Benfield (2012) '2011 Thailand Floods Event Recap Report'. Available at: http://thoughtleadership.aonbenfield.com/Documents /20120314_impact_forecasting_thailand_flood_event _recap.pdf (Accessed: 10-May-2013).

2. Munich Re (2012) Topics Geo, Natural catastrophes 2011: Analyses, assessments, positions. Munich Reinsurance Company. Munich, Germany.

3. Nanto, D.K., Cooper, W.H. and Donnelly, J.M. (2011) 'Japan's 2011 Earthquake and Tsunami: Economic Effects and Implications for the United States', Congressional Research Service, Report R41702.

4. Lifset, R. (2009) 'Industrial Ecology in the Age of Input-Output Analysis', in Suh, S. (ed.) Handbook of Input-Output Economics in Industrial Ecology. London: Springer.

5. Pant, R., Barker, K., Grant, F.H. and Landers, T.L. (2011) 'Interdependent impacts of inoperability at multi-modal transportation container terminals', Transportation Research Part E-Logistics and Transportation Review, 47(5), pp. 722-737.

6. Amaral, L.A.N. and Ottino, J.M. (2004) 'Complex networks - Augmenting the framework for the study of complex systems', European Physical Journal B, 38(2), pp. 147-162.

7. Fu, G., Dawson, R. J., Khoury, M. and Bullock, S. (2014) 'Interdependent networks: Vulnerability analysis and strategies to limit cascading failure', European Physical Journal Part B, 87(7):148.

8. Leontief, W. (1970) 'Environmental Repercussions and Economic Structure - Input-Output Approach', Review of Economics and Statistics, 52(3), pp. 262271.

9. Hawkins, T., Hendrickson, C., Higgins, C., Matthews, H.S. and Suh, S. (2007) 'A mixed-unit input-output model for environmental life-cycle assessment and material flow analysis', Environ Sci Technol, 41(3), pp. 1024-31.

10. Duchin, F. and Levine, S.H. (2008) 'Tracking Global Factor Inputs, Factor Earnings, and Emissions Associated with Consumption in a World Modeling 
Framework', Rensselaer Working Papers in Economics, 0714a, pp. 1-38.

11. Scipy (2013) Numpy and Scipy Documentation. Available at: http://docs.scipy.org/doc/ (Accessed: 01-March-2016).

12. NetworkX (2012) NetworkX documentation. Available at: http://networkx.github.io/documentation/latest/index. html (Accessed: 01-March-2016).

13. Pickett, S.T.A., Cadenasso, M.L. and Grove, J.M. (2004) 'Resilient cities: meaning, models, and metaphor for integrating the ecological, socioeconomic, and planning realms', Landscape and Urban Planning, 69(4), pp. 369-384.

14. Wang, J. (2013) 'Robustness of complex networks with the local protection strategy against cascading failures', Safety Science, 53(0), pp. 219-225.

15. Hallegatte, S. (2008) 'An adaptive regional inputoutput model and its application to the assessment of the economic cost of Katrina', Risk Analysis, 28(3), pp. 779-799.

16. Salles, R.M. and Marino, D.A. (2012) 'Strategies and Metric for Resilience in Computer Networks', Computer Journal, 55(6), pp. 728-739.

17. Newlands, D. and Roberts, D. (2006) 'Shetland Regional Accounts 2003'. Scotland: University of Aberdeen Business School

18. SIC (2013) Strategic Flood Risk Assessment. Available at: http://www.shetland.gov.uk/planning/documents/Stra tegicFloodRiskAssessmentcomplete.pdf (Accessed: 01/04/2016).

19. NYC (2013) 'New York City: A Stronger, More Resilient New York' www.nyc.gov/html/sirr/html/report/report.shtml (Accessed: 01-March-2016).

20. EIA (2012) New York City Metropolitan Area Retail Motor Gasoline Supply Report, https://www.eia.gov/special/disruptions/hurricane/sa ndy/gasoline_updates.cfm

21. Dietrich, S. (2012) Hurricane Sandy and the Food Supply Chain. Available at: http://blog.lib.umn.edu/tfic/foodthought/2012/12/hur ricane-sandy-and-the-foodsupply-chain.html (Accessed: 01/04/2016)

22. FEMA (2014) Hurricane Sandy: Timeline. Available at: Www.fema.gov/hurricane-sandy-timeline (Accessed: 01/04/2016)

23. Diaz, J. (2012) The Complete Story of Sandy: a Timeline of Horror and Recovery. Available at: http://gizmodo.com/5955575/hurricane-sandysatellite-photos-andvideos-updating-live (Accessed: 01/04/2016)

24. Drye, W. (2012) A Timeline of Hurricane Sandy's Path of Destruction. Available at:http://voices.nationalgeographic.com/2012/11/02/a -timeline-of-hurricane-sandyspath-of-destruction/ (Accessed: 01/04/2016) 